\title{
Compression Myelopathy due to Proliferative Changes around C2 Pars Defects without Instability
}

\author{
Tetsuya Kimura, Toshinori Sakai, Fumitake Tezuka, Mitsunobu Abe, \\ Kazuta Yamashita, Yoichiro Takata, Kosaku Higashino, Koichi Sairyo \\ Department of Orthopedics, Institute of Health Biosciences, The University of Tokushima Graduate School, Kuramoto, Japan
}

\begin{abstract}
We report a case with compression myelopathy due to proliferative changes around the $\mathrm{C} 2$ pars defects without instability. A 69-yearold man presented with progressive clumsy hands and spastic gait. Plain radiographs showed bilateral spondylolysis (pars defects) at C2 and fusion between C2 and C3 spinous processes. Dynamic views revealed mobility through the pars defects, but there was no apparent instability. Computed tomography showed proliferative changes at the pars defects, which protruded into spinal canal. On magnetic resonance imaging, the spinal cord was compressed and intramedullary high signal change was found. A diagnosis of compression myelopathy due to proliferative changes around the $\mathrm{C} 2$ pars defects was made. We performed posterior decompression. Postoperatively, symptoms have been alleviated and images revealed sufficient decompression and no apparent instability. In patients with the cervical spondylolysis, myelopathy caused by instability or slippage have been periodically reported. The present case involving C2 spondylolysis is extremely rare.
\end{abstract}

Keywords: Axis; Cervical vertebra; Spondylolysis; Spinal cord compression

\section{Introduction}

Spondylolysis is a condition defined as a bony defect at the pars interarticularis in the spine [1,2]. Lumbar spondylolysis is not a rare condition and is reported to occur in around 6\% of the general population [3-5]. In contrast, cervical and thoracic spondylolysis is an uncommon entity [6], and in regard to axis (C2) spondylolysis, only 30 cases have been reported in the literature $[1,7]$. The etiology of spondylolysis has not been established, with congenital and a fatigue fracture, but many clinical studies have supported a stress fracture [8].
In patients with lumbar spondylolysis, spondylolisthesis with or without low back pain sometimes occurs once the pars defect is completed $[9,10]$. Also, proliferative changes around the pars defects sometimes produce radiculopathy by compressing the nerve root, and surgical treatment is required [11]. In patients with cervical spondylolysis, myelopathy caused by instability or slippage has been reported [1]. However, no English literature has described a case with myelopathy due to proliferative changes around pars defects.

In this paper, we present a case of C2 spondylolysis with myelopathy caused by proliferative changes around

Received Nov 3, 2015; Revised Dec 1, 2015; Accepted Dec 1, 2015

Corresponding author: Toshinori Sakai

Department of Orthopedics, Institute of Health Biosciences, The University of Tokushima Graduate School,

3-18-15 Kuramoto, 770-8503 Tokushima, Japan

Tel: +81-88-633-7240, Fax: +81-88-633-0178, E-mail: norinoridowluck@yahoo.co.jp 
the pars defects on the C2 lamina, and not caused by instability.

\section{Case Report}

\section{History}

A 69-year-old male had an 8-year history of paresthesia from forearm to hand on the right side with no experience of any obvious traumatic episodes. He was referred to our hospital because of progressive difficulty in walking and numbness in his extremities.

\section{Physical examination}

Physical examination revealed normal strength in all limbs but clumsy hands and bilateral numbness on both arms. The deep tendon reflexes were hyperactive bilaterally below C5 level and his gait was spastic. Pathological reflexes including scapulohumeral reflex, Hoffmann's sign, Wartenberg's sign, and Babinski's sign were negative and he had no bladder and bowel dysfunctions.
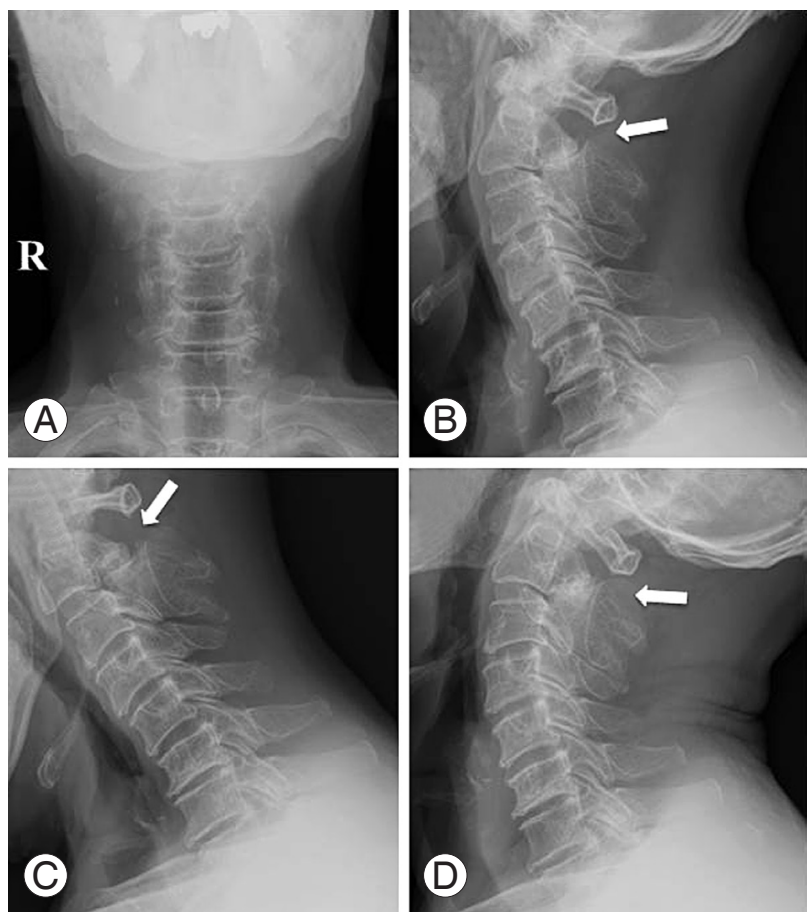

Fig. 1. Anteroposterior (A), lateromedial (B), flexion (C), and extension (D) plain radiography views of the cervical spine. Plain radiography shows spondylolysis at C2 (white arrows) and fusion between $\mathrm{C} 2$ and $\mathrm{C} 3$ spinous process. Flexion and extension plain radiography reveal mobility between $\mathrm{C} 2$ and C3 but no apparent instability.

\section{Radiological findings}

Plain radiographs of the cervical spine showed bilateral spondylolysis at $\mathrm{C} 2$ and bony fusion between the $\mathrm{C} 2$ and C3 spinous processes (Fig. 1A, B). Dynamic views revealed mobility between $\mathrm{C} 2$ and $\mathrm{C} 3$ through the spondylolysis. Obvious intervertebral instability was not found at any spinal levels (Fig. 1C, D). Computed tomography (CT) of the cervical spine revealed a sclerotic margin with a triangular configuration of the pillar fragments on both sides the spondylolytic defect. Proliferative "ragged edge" changes were detected around the bilateral pars defects, which protruded into spinal canal (Fig. 2A, B). Magnetic resonance imaging (MRI) of the cervical spine revealed cervical spinal canal stenosis. The spinal cord was severely compressed at the $\mathrm{C} 2$ level, and high signal change was found in the spinal cord on T2 weighted-images (Fig. 2C, D).

\section{Surgical treatment}

We performed $\mathrm{C} 2-\mathrm{C} 3$ posterior decompression for $\mathrm{C} 2$
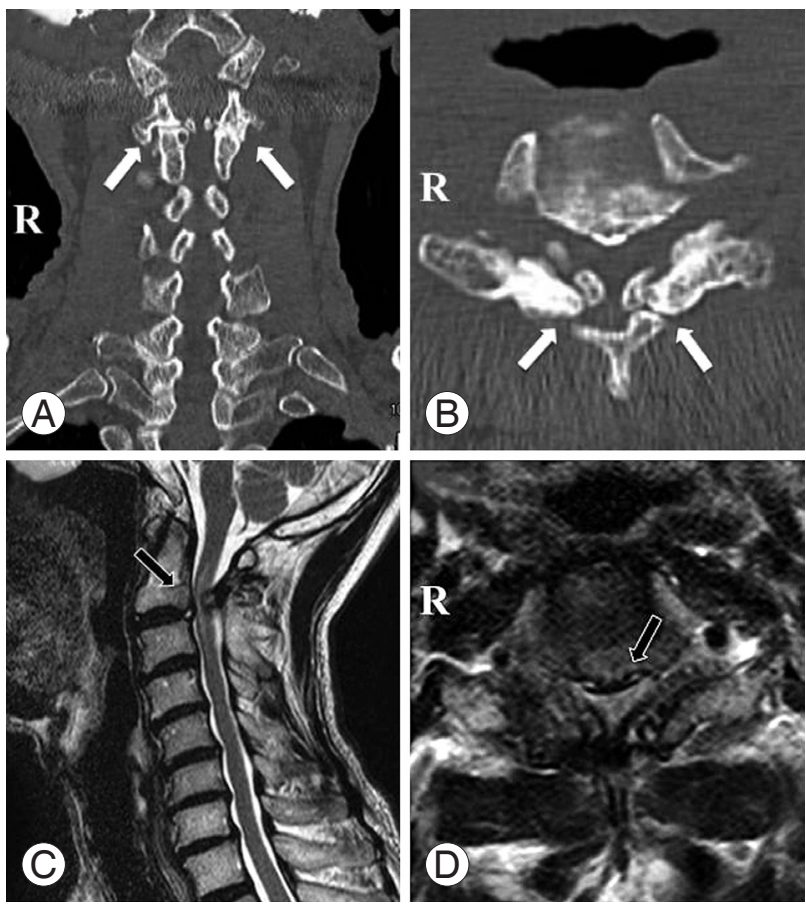

Fig. 2. Coronal (A) and axial (B) computed tomography (CT), and sagittal (C) and axial (D) T2 weighted magnetic resonance imaging (MRI). CT reveals bilateral spondylotic defect at $\mathrm{C} 2$ and ragged edge at ventral aspect of bilateral pars defect (white arrows). MRI reveals cervical spinal canal stenosis and high intensity in spinal cord at C2-C3 (black arrows). 
spondylolysis. C2 spondylolysis was recognized and proliferation of synovial membrane existed around the pars defect. We performed total laminectomy at the C2 and partial laminectomy at C3. Ragged edge existed at the ventral aspect of the pars defect and compressed the dura mater bilaterally. Complete decompression of the dura mater was achieved.

\section{Postoperative course}

The postoperative course was uneventful. Clumsiness of both hands and difficulty in walking were alleviated. Plain radiography taken after one year postoperatively revealed no apparent instability (Fig. 3A-C). MRI scan two months postoperatively showed sufficient decompression of C2C3 (Fig. 3D).

\section{Discussion}

Spondylolysis commonly occurs in the lumbar spine and is present in around $6 \%$ of the population $[3-5,12]$. However, cervical spondylolysis is exceedingly rare, and
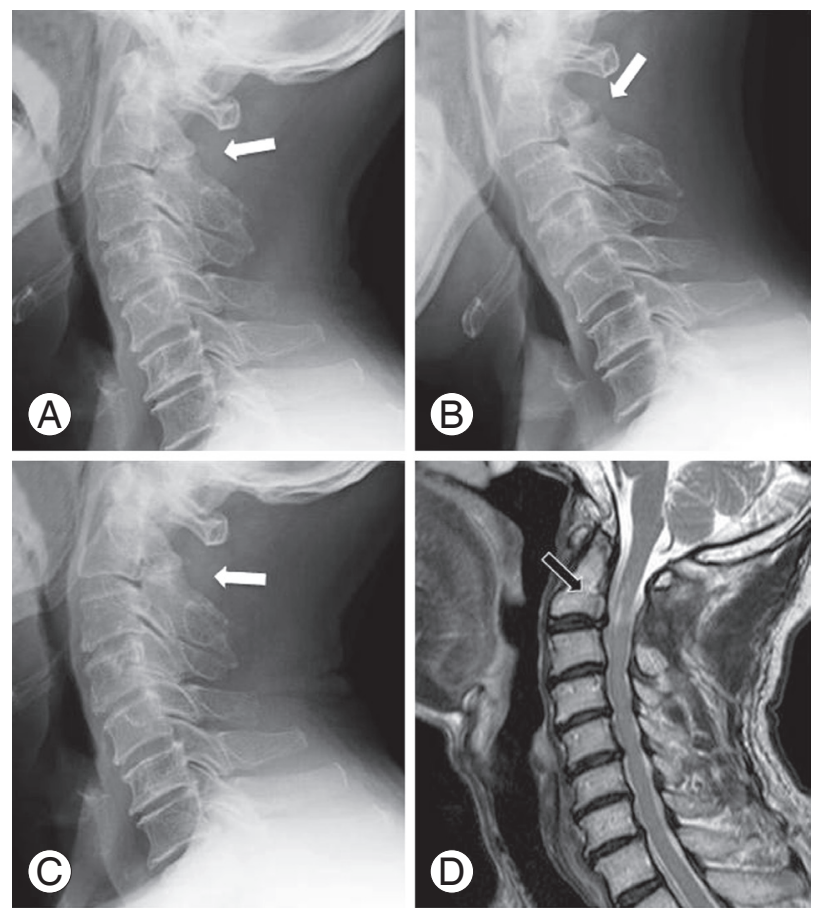

Fig. 3. Lateromedial (A), flexion (B), and extension (C) plain radiographs taken one year postoperatively. Sagittal (D) T2 weighted magnetic resonance imaging (MRI) taken two months postoperatively. Plain radiography and $\mathrm{MRI}$ reveal no obvious instability (white arrows) and sufficient decompression of C2-C3 (black arrow). in regard to spondylolysis of $\mathrm{C} 2$, only 30 cases have been reported in the literature $[1,6]$. Gehweiler et al. [13] reported the first case of spondylolysis of C2 in 1977. Various symptoms of the cervical spondylolysis have been reported and include a clicking neck, neck pain, motionassociated pain, radiculopathy, and myelopathy that is sometimes diagnosed incidentally $[2,14]$.

In the absence of specific symptoms, radiological findings are vital for making a correct diagnosis of cervical spondylolysis. In addition, the diagnosis should be distinguished from an acute fracture, such as a hangman's fracture. Previous reports outlined several points in this point. Nishimura et al. [1] proposed a differentiation based on CT involving a well-margined cleft or a sclerotic margin with a triangular configuration of the pillar fragments on either side of the spondylolytic defect, compensatory hyper- or hypoplasia of the ipsilateral articular pillars at the level above and/or below the defect, and the presence of associated dysplastic changes at the involved level. MRI is ineffective in delineating the bony architecture of the cervical spine, but is useful for assessment of the acuteness of the injury according to the presence of edema in the softtissue and bony structures, condition of the spinal cord, and presence of associated disc herniations around the involved segment $[2,15,16]$.

Basically, surgical treatment for the cervical spondylolysis is directed in cases with symptoms, instability, spinal cord compression, and neurologic deficit $[1,6]$. Among 30 patients with C2 spondylolysis who have been reported previously, only six underwent surgery. In addition, all of the patients required intervertebral fusion due to $\mathrm{C} 2-\mathrm{C} 3$ instability. None of 21 patients without C2-C3 instability required surgical treatment (Table 1) [1,7,12,13,17-19].

In lumbar spondylolysis, once the pars defect is completed, two pathological entities are considered. The first is slippage and low-back pain. The second is pseudarthrosis of a fractured pars defect produces radiculopathy by compressing the nerve root [9-11,20]. Ragged edge around the pars defect is the most frequent contributing factor for radiculopathy and surgical treatment is sometimes required [11]. However, such an entity has not been reported in the cervical spine. In our case, it was considered as the proliferative changes due to the mobility around the pars defects, which is a mechanism similar to pseudoarthrosis of the long bone. We believe this is the first case with myelopathy due to the ragged edge at the ventral aspect of bilateral pars defects, not due to $\mathrm{C} 2-\mathrm{C} 3$ 


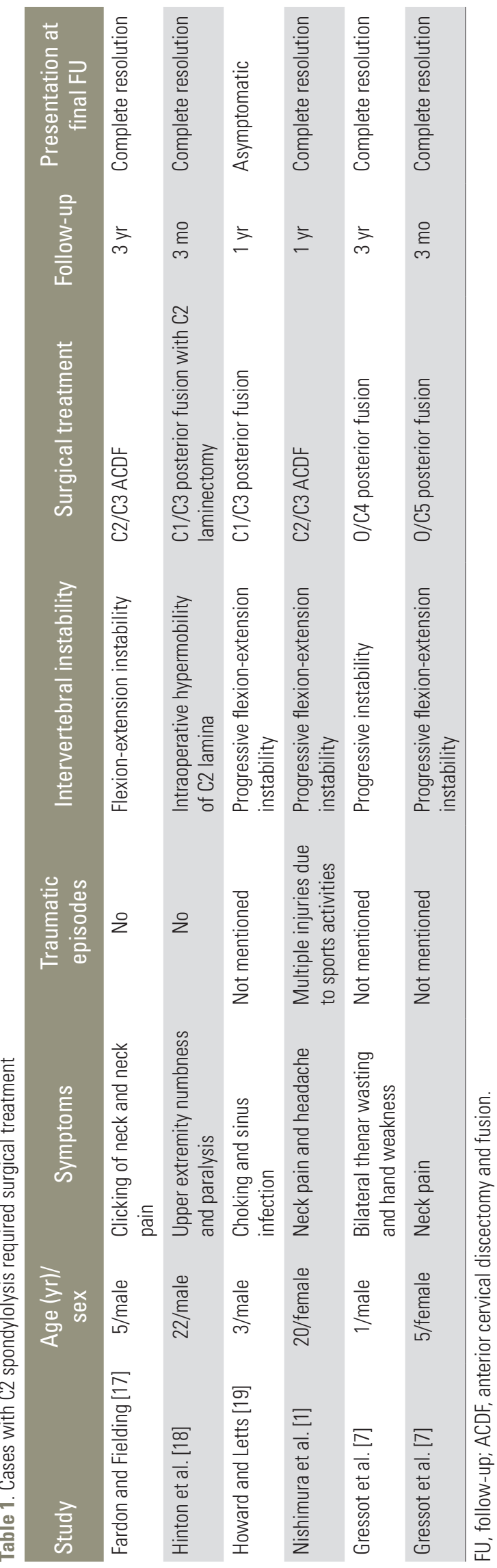

intervertebral instability.

\section{Conflict of Interest}

No potential conflict of interest relevant to this article was reported.

\section{References}

1. Nishimura Y, Ellis MJ, Anderson J, Hara M, Natsume A, Ginsberg HJ. Progressively unstable c2 spondylolysis requiring spinal fusion: case report. Neurol Med Chir (Tokyo) 2014;54:761-7.

2. Paik NC. Bilateral cervical spondylolysis of C7. Spine J 2010;10:e10-3.

3. Beutler WJ, Fredrickson BE, Murtland A, Sweeney CA, Grant WD, Baker D. The natural history of spondylolysis and spondylolisthesis: 45-year followup evaluation. Spine (Phila Pa 1976) 2003;28:102735.

4. Fredrickson BE, Baker D, McHolick WJ, Yuan HA, Lubicky JP. The natural history of spondylolysis and spondylolisthesis. J Bone Joint Surg Am 1984;66:699707.

5. Sakai T, Sairyo K, Takao S, Nishitani H, Yasui N. Incidence of lumbar spondylolysis in the general population in Japan based on multidetector computed tomography scans from two thousand subjects. Spine (Phila Pa 1976) 2009;34:2346-50.

6. McAnany S, Cho S, Qureshi S, Hecht AC. A commentary on cervical spondylolysis in the contact athlete. Spine J 2014;14:e7-8.

7. Gressot LV, Vadivelu S, Hwang SW, Fulkerson DH, Luerssen TG, Jea A. Spondylolysis of C-2 in children 3 years of age or younger: clinical presentation, radiographic findings, management, and outcomes with a minimum 12-month follow-up. J Neurosurg Pediatr 2014;13:196-203.

8. Sairyo K, Katoh S, Ikata T, Fujii K, Kajiura K, Goel VK. Development of spondylolytic olisthesis in adolescents. Spine J 2001;1:171-5.

9. Saraste H. Spondylolysis and spondylolisthesis. Acta Orthop Scand Suppl 1993;251:84-6.

10. Sairyo K, Sakai T, Mase Y, et al. Painful lumbar spondylolysis among pediatric sports players: a pilot MRI study. Arch Orthop Trauma Surg 2011;131:1485-9.

11. Sairyo K, Katoh S, Sakamaki T, Komatsubara S, Yasui 
N. A new endoscopic technique to decompress lumbar nerve roots affected by spondylolysis. Technical note. J Neurosurg 2003;98:290-3.

12. Gottfried ON, Parker SL, Omeis I, Bydon A, Gokaslan ZL, Wolinsky JP. Spondylolysis of C-2 in 2 athletically active individuals. J Neurosurg Spine 2010;13:17-23.

13. Gehweiler JA Jr, Martinez S, Clark WM, Miller MD, Stewart GC Jr. Spondylolisthesis of the axis vertebra. AJR Am J Roentgenol 1977;128:682-1.

14. Ahn PG, Yoon DH, Shin HC, et al. Cervical spondylolysis: three cases and a review of the current literature. Spine (Phila Pa 1976) 2010;35:E80-3.

15. Mofidi A, Tansey C, Mahapatra SR, Mirza HA, Eisenstein SM. Cervical spondylolysis, radiologic pointers of stability and acute traumatic as opposed to chronic spondylolysis. J Spinal Disord Tech 2007;20:473-9.

16. Schwartz JM. Case 36: bilateral cervical spondylolysis of C6. Radiology 2001;220:191-4.

17. Fardon DF, Fielding JW. Defects of the pedicle and spondylolisthesis of the second cervical vertebra. J Bone Joint Surg Br 1981;63:526-8.

18. Hinton MA, Harris MB, King AG. Cervical spondylolysis: report of two cases. Spine (Phila Pa 1976) 1993;18:1369-72.

19. Howard AW, Letts RM. Cervical spondylolysis in children: is it posttraumatic? J Pediatr Orthop 2000;20:677-81.

20. Shiraishi T, Crock HV. Excision of laminal pseudoarthroses in spondylolytic spondylolisthesis: a review of 13 cases. Eur Spine J 1995;4:52-5. 